\title{
Construction and Comparison of a Correlation Model on the Marketing Effect of Cultural and Creative Landmarks on Regional Tourism Development
}

\author{
Shwu-Ing $\mathrm{Wu}^{1}$ \\ ${ }^{1}$ Department of Business Administration, National Chin-Yi University of Technology, Taiwan, R.O.C. \\ Correspondence: Shwu-Ing Wu, Department of Business Administration, National Chin-Yi University of \\ Technology, Taiping, Taichung, Taiwan. Tel: 886-4-23924505. E-mail: wusi@ncut.edu.tw
}

Received: May 17, 2017

Accepted: June 15, 2017 Online Published: August 3, 2017

doi:10.5539/jms.v7n3p90

URL: http://doi.org/10.5539/jms.v7n3p90

\begin{abstract}
The marketing of cultural and creative landmarks has become important ever since it has been associated with the connection between regional development and people's needs, thus making it is an urgent issue of regional tourism sustainability. From Taipei, Taichung, and Kaohsiung of Taiwan, this study respectively selects one cultural and creative landmark that represents the city as the targets and explores tourists who have visited any of these landmarks in order to analyze the effects of characteristics, surroundings, and marketing activities of cultural and creative landmarks on the public's perceived value and regional attraction. It also constructs a correlation model. After analyzing 578 valid questionnaires, this study realizes that surroundings are the most critical factor influencing people's perceived value of cultural and creative landmarks and enhance a regional attraction; the second most critical factor is the effect of landmark characteristics. However, the impact of marketing activities is insignificant. It shows that people' perception of the marketing activities of cultural and creative landmarks is low. Therefore, in the future the marketing activities of cultural and creative landmarks should come from the aspect of improvement.
\end{abstract}

Keywords: cultural and creative landmarks, perceived value, regional attraction

\section{Introduction}

People's knowledge about the world in recent years has increased immensely, reinforcing their desire for diverse travel experiences. They intend to approach different cultures in different regions by travel, resulting in the strong development of the global tourism industry (Ministry of Culture, 2013). Hence, governments and industries of different countries are all making efforts to promote buildings and sites with local cultural features in order to attract visitors through these characteristics that are different from other areas. Thus, they enhance the local tourism industry and national development. "Cultural and creative industry" has become one of the key items actively developed by many governments. The development of this industry is based on local culture, historic landscape, and local characteristics, and the scope is extremely broad (Montgomery, 2004). Without significant and unique objects to reinforce people's impression and memory, the outcome can be ineffective. Therefore, an essential condition to promote local characteristics is the construction of impressive buildings as local landmarks to strengthen people's impression by physical forms.

Cultural and creative landmarks can highlight local characteristics, reinforce a regional image, attract tourists, enhance commercial activities, increase local revenues, and result in outcomes of diverse development (Montgomery, 2003). However, cultural and creative parks established in different areas can be similar, and they might even not highlight the characteristics and not play the roles of landmarks. Thus, after the activities are finished and people all leave, can cultural and creative parks continue to be impressive and become public landmarks? Will they become regular destinations and accomplish the advantage of sustainable development in their region? These are questions worth a further study.

In the process of globalization, boundaries among regions and groups are disappearing and appearances are becoming similar. Thus, local cultural characteristics and buildings are one of the keys to preserve a local appearance. Cultural and creative landmarks construct a brand new urban image by culture and originality and can help assemble resources and tourists (Montgomery, 2004). Hence, cultural and creative parks are the key of many countries to strengthen national economic development and the main strategy of urban revival. The 
purpose is to enhance local culture and strengthen the urban economic base, urban marketing, and competitiveness (Kotler, Haider, \& Rein, 1993). With the establishment of various cultural and creative parks, another issue is how to implement a marketing strategy and draw consumers' attention in order to transform them into important landmarks and regular tourist spots.

The government of Taiwan in recent years has put forth great efforts on the construction of cultural and creative industry parks, resulting in the rise of many new parks, such as Taipei Songshan Cultural and Creative Park, Kaohsiung Pier-2 Art Center, Taichung Cultural and Creative Industries Park, etc. They are the bases of development of the country's cultural and creative industry and even have become well-known local landmarks. Nevertheless, with such a diversity of cultural and creative parks and themes, can they form individual characteristics? Will they become people's cognitive landmarks in the regions? With they draw the public's attention and enhance their interest through marketing activities? Will the surroundings become a target of people's visits? Will they influence people's value perception toward the regions and result in regional attraction? These are important questions to investigate.

Based on previous research backgrounds and motives, this study respectively selected one representative cultural and creative landmark from three cities in northern, central, and southern Taiwan (Taipei Songshan Cultural and Creative Park, Kaohsiung Pier-2 Art Center, and Taichung Cultural and Creative Industries Park) as the targets to analyze their characteristics, surroundings, and marketing activities and their effects on people's perceived value and regional attraction to further recognize the dimensions with the greatest effect and to construct a correlation model.

\section{Literature Review}

\subsection{Surroundings}

Regional image is people's overall idea and impression on an area, and it is significantly influenced by their total view on the surroundings of the region (Crompton, 1979). Therefore, the surroundings of an area are the key factor of regional development, the public's expectation toward the region, and influence people's decision-making of travel and residence (Leisen, 2001; Fakeye \& Crompton, 1991). Martin \& Del Bosque (2008) classified regional image into infrastructure, social and economic environment, atmosphere, natural environment, emotional image, and cultural environment. The image results in people's total feelings toward the surroundings of one region.

Surroundings affect the image of one area for tourists (Harrell, Hutt, \& Anderson, 1980). Thus, when the overall image of the surroundings of cultural and creative landmarks matches tourists' expectation, the tourists will be satisfied (Jochen \& John, 1999). Therefore, tourists regard surroundings as a perceived value factor of travel. Customers evaluate the quality of stores by the surroundings and conclude the value acquired as the criterion of their repurchase (Baker et al., 2002). Likewise, people treat surroundings of a region as a concern for their following travel or stay. Surroundings such as natural landscape, historic relics, and local scenery influence people's emotion and behavior (Bitner, 1992) and further affect the reaction of consumer behavior (Bitner, Barnes, \& Ward, 1992; Wu \& Zheng, 2014). Beerli \& Martín (2004) proposed five dimensions of the image of travel areas: natural and cultural resources, public recreation and facilities, atmosphere, safe environment, and tourist resources. They form people's overall environmental view and affect tourists' emotion.

Cultural and creative landmarks of many regions in Taiwan tend to be based on historical old streets and cultural relics, natural landscape, diverse designs, and local snacks. Thus, according to previous scholars' classification of regional image, this study divides the dimension of a region's surroundings into natural landscape, cultural relics, infrastructure, and local characteristics as items to measure surroundings of cultural and creative landmarks.

\subsection{Landmark Characteristics}

Many cities in the world are known by their famous buildings or landscape, which even become the image and representative of those places and people's beliefs and cognition of those regions. This is the concept of landmark (Kotler et al., 1993). The image of one region combined with local spots and various building characteristics result in an overall image (MacKay \& Fesenmaier, 1997). A key success factor for regional or urban development is the creation of a regional image (Chen \& Kerstetter, 1999; Crompton, 1979). Thus, landmarks with characteristics tend to strengthen the creation of a regional image. Consumers can infer or confirm the perceived quality of products by their brand image cognition (Richardson, Dick, \& Jain, 1994); likewise, landmark characteristics can be the prediction factor of regional quality. Therefore, in many cities or areas, characteristic buildings or landscape are established in order to be impressive and representative landmarks and even enhance the positive regional image for people. 
Cultural and creative landmarks should include factors such as recreational function, recreation \& entertainment, social education, and quality symbols. As suggested by Park, Jaworski, \& MacInnis (1986), people have different needs for benefits as follows: 1) functional benefit: it assists individuals to solve problems; 2) symbolic benefit: it satisfies individuals' internal needs, such as enhancement of personal value and compatibility in groups; and 3) experiential benefit: it satisfies individuals' desired playfulness. Thus, this study includes the perspective of the needs for benefits in landmark marketing, and from 3 dimensions of benefit proposed by Park, Jaworski \& MacInnis, it attempts to find whether landmark characteristics of different regions meet people's relative needs for benefits.

\subsection{Marketing Activity}

The introduction of marketing in regional development has been the trend over time and can improve the economic, social, and cultural dimensions of regions (Wu \& Liou, 2015). Therefore, regional marketing activities can promote landmarks and products with regional characteristics to accomplish the goal of sustainable development (Kotler et al., 1993). Armstrong \& Kotler (2000) argued that a regional marketing strategy can be generalized into four items: 1) image marketing; 2) attraction marketing; 3) infrastructure marketing; and 4) public marketing. It thus reinforces the attraction of the regions and the public's positive attitude.

The application of marketing in a regional development strategy can reinforce the reputation and image of the areas and trigger overall economic activity that can subsequently lead to the vision of sustainable development. Thus, based on the four dimensions of regional marketing proposed by Armstrong \& Kotler (2000), this study explores the content of regional marketing. However, since infrastructure marketing in four marketing strategies is included in one independent variable of this study, surroundings, this study generalizes image marketing, attraction marketing, and the public's word-of-mouth as items to measure regional marketing activities.

\subsection{Perceived Value}

Perceived value is users' evaluation on utility provided by products or services, and it is users' concern between "contribution" of products or services and "feedback" (Dodds, Monroe, \& Grewal, 1991). In certain areas, perceived value can be denoted as the exchange between benefits or advantages acquired by visiting the place and the energy, time, and money paid by people. Based on the concept proposed by Zeithaml (1988), perceived value can be generalized into 4 views: 1 ) value is low price; 2) value means consumers acquire the products they desire; 3 ) value is the equality between prices paid by consumers and quality obtained; and 4) value is the price paid by consumers to obtain what they desire.

Regarding people's perceived value of a certain region, the public's personal senses, perception, and behavior continuously contact or interact with surroundings, and they obtain valuable perception and experience from the process (Schmitt, 1999). Thus, what is valuable for the public is not only the physical products or environment, but also the experience and ultimate value obtained. By sentimental emotion, they intend acquire a delightful and unforgettable memory (Pine \& Gilmore, 2003).

Sweeney \& Soutar (2001) classified perceived value of experiential activities into emotion, society, price, and quality. Schmitt (1999) proposed an experimental framework of sense, emotion, thought, action, and correlation, which can serve as dimensions to measure travel experience. In the process of regional development, the public's experience can trigger their affection, curiosity, and perception of image of the place. Thus, appealing experience is the key to a positive perceived value.

This study explores the public's perceived value and feelings toward cultural and creative landmarks. Hence, based on the concepts of perceived value mentioned by previous scholars, this study designs variables of perceived value through five concepts: functional value, social value, emotional value, playful value, and aesthetic value.

\subsection{Regional Attraction}

The public's visit or residential intention to go to a certain region is an indicator of regional attraction since positive development in the region can result in people's visit or stay. In terms of individuals' behavioral process, according to their experience, people prefer or detest objects or events, and it influences their behavioral intention and actual behavior (Cronin \& Taylor, 1992). Hence, the concept of behavioral intention can be applied to a measurement of regional attraction.

Blackwell et al. (2001) proposed five dimensions to measure consumers' behavioral intention: 1) purchase intention; 2) repurchase intention; 3) procurement intention; 4) expenditure intention; and 5) consumption intention. Boulding et al. (1993) and Cronin et al. (2000) stated that dimensions of consumers' behavioral intention include repurchase intention, recommendation to others, and intention to pay more money. Gronholdt, 
Martensen, \& Kristensen (2000) applied behavioral intention to measurement on tourists' loyalty to a certain region, including: 1) revisit intention: tourists' intention to revisit; 2) recommendation intention: tourists' intention to recommend a certain region to others and enhance others' visit intention; 3) price endurance: tourists can endure all prices in the region; and 4) extended behavior: tourists actively construct positive word-of-mouth of a certain region to attract more visitors.

This study integrates the behavioral intention perspectives proposed by previous scholars and applies them in the exploration of regional attraction. It generalizes visit intention, revisit intention, residential intention, and recommendation intention as the items to measure regional attraction.

\section{Construction of Research Hypotheses}

\subsection{Relationship between Surroundings and Perceived Value}

People tend to be influenced by the surroundings of certain areas, which trigger their perception and determine their behavior. For instance, environmental factors of certain regions such as natural landscape, cultural relics, infrastructure, and local characteristics influence people's cognition, emotion, and behavior (Bitner, 1992). Likewise, the atmosphere created by stores, the locations of commercial circles, and parking lots form the overall image of stores and surroundings. When consumers identify with the said image, they have positive emotion, which enhances their perceived value and results in ultimate consumer behavior (Jochen \& John, 1999). Thus, surrounding factors influence the public's perceived value of the spots (Baker et al., 2002). Bigne et al. (2001) and $\mathrm{Wu} \&$ Huang et al. (2015) demonstrated that when tourists' preference for the surroundings of certain regions is more significant, their evaluation on the quality of the places will be higher. Baker (2006) stated that consumers' positive interaction with surroundings positively influences experiential value - that is to say, when tourists identify with surroundings of the region, their perceived value of the place is higher. Thus, surroundings and situational design factors are the key successful conditions of the service industry (Baker, Parasuraman, Grewal, \& Voss, 2002). Based on the above, positive surroundings result in consumers' higher perceived value. Thus, when the atmosphere created by the surroundings of cultural and creative landmarks in different regions meets people's expectation, it will trigger their emotional value perception (Babin, Darden, \& Griffin, 1994). Thus, this study constructs the hypothesis below.

H1: When the surroundings of cultural and creative landmarks are more popular, their perceived value will be higher.

\subsection{Relationship between Landmark Characteristics and Perceived Value}

Regional image tends to be conceived as a key factor of tourists' quality perception and revisit intention, and it can be employed to infer tourists' perceived value of the area (Keller, 1993; Agarwal \& Teas, 2004). When regional image has more characteristics or is more different, people perceive the unique and memorable aspects, and thus their perceived value is higher (Wu \& Huang, 2015; Schmitt, 1999). When tourists' perceived value of certain region is higher, it enhances their visit intention (Romaniuk \& Sharp, 2003).

It is thus inferred that differential characteristics of cultural and creative landmarks draw people's attention and even reinforce perceived value and visit intention. According to benefit dimensions proposed by Park, Jaworski, \& MacInnis (1986), this study generalizes 3 landmark characteristics of functional benefit, symbolic benefit, and hedonic benefit for the discussion. Thus, it argues that when cultural and creative landmarks of different regions are based on: 1) functional benefit: it provides people with the place for leisure activities; 2) symbolic benefit: it satisfies the interaction between individuals and groups and enhances life quality and self-satisfaction; 3) hedonic benefit: it satisfies individuals' expected playfulness, diverse activities, and excitement in life, they can enhance the public's perceived value. Based on the above, the next hypothesis is shown below.

H2: When the characteristics of cultural and creative landmarks are more popular, perceived value will be higher.

\subsection{Relationship between Marketing Activities and Perceived Value}

The purpose for holding marketing activities in regions is to allow tourists to perceive the stimulus after participating in the activities, which results in identification. It can also enhance their perceived value (Schmitt, 1999). Based on this concept, successful marketing activities of cultural and creative landmarks will result in tourists' identity and attachment with the regions, and they become live advertising, thus enhancing the intention to interact with the region (Turner, 2001). When unique and stylish experiences are created in the marketing activities of cultural and creative landmarks, tourists' perceived value will be upgraded. Hu \& Ritchie (1993) also demonstrated that tourists' perceived value of destinations derives from satisfaction, view, and cognition with the marketing activities provided. Thus, it is inferred that the marketing activities of cultural and creative 
landmarks significantly and positively influence the public's perceived value. Based on the above, this study constructs the next hypothesis.

H3: When the marketing activities of cultural and creative landmarks are more popular, perceived value will be higher.

\subsection{Relationship between Perceived Value and Regional Attraction}

Individuals' perceived value of things directly and positively influences their attitude and acceptance (Lee, Uniremidy, \& Overby, 2004). According to Chen \& Quester (2006), customers' perceived value enhances their repurchase intention and recommendation to others; attraction of the stores for customers thus increases. Cronin et al. (2000) proposed the correlation model among service quality, customer satisfaction, and service value. They demonstrated that customers' perceived value of the service industry positively enhances their future purchase intention. This study focuses on cultural and creative landmarks and regional attraction, including visit intention, revisit intention, residential intention, and recommendation intention. Hence, according to previous perspectives, it is inferred that when the public's perceived value of cultural and creative landmarks is higher, it enhances the attraction of the region. Based on the above, this study constructs another hypothesis.

H4: When the public's perceived value of cultural and creative landmarks is higher, the regional attraction will be greater.

\section{Research Design}

\subsection{Research Framework}

Based on the previous literature review, this study establishes hypotheses and research structure. Through qualitative research, questionnaire design, and sampling investigation and analysis, it validates the hypotheses and constructs a conceptual model. Figure 1 illustrates the research framework.

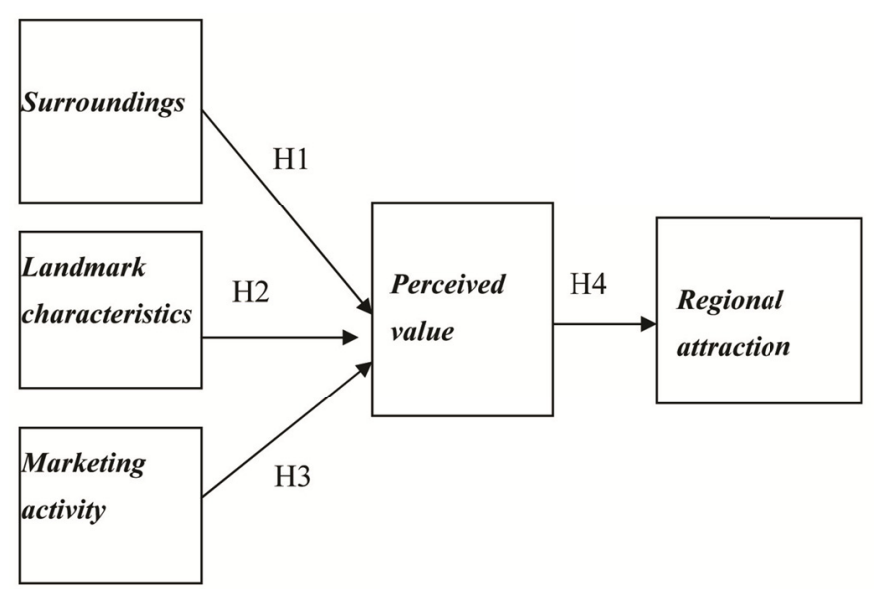

Figure 1. Research framework

\subsection{Research Method}

This study first adopted the focus group method of qualitative research that including 10 tourists and 10 researchers to select cultural and creative landmarks for the public from northern, central, and southern Taiwan (Taipei Songshan Cultural and Creative Park, Kaohsiung Pier-2 Art Center, and Taichung Cultural and Creative Industries Park); subsequently, it collected related theories and literatures as reference of research framework. Through the second focus group, it interviewed 10 participants of cultural and creative landmarks in different regions in order to organize the key content of the research dimensions and to establish related measurement indicates. Based on the content and indicators, it designed the questionnaire. Through in-depth interviews, it conducted a pre-test of 50 questionnaires, revised the terms, and validated the questionnaire content. It thus collected primary data in order to probe into the public's view toward characteristics, surroundings, marketing activities, perceived value, and regional attraction of cultural and creative landmarks in different regions and to establish a structural relationship model. As to the scale of the questionnaire, except for the subjects' background, which was measured by a nominal scale, the others were measured by a 7-point scale. One to 7 points refer to strongly disagree to strongly agree. 
This study treated the public in Taiwan as subjects. For the concern of effect of the questionnaire, the subjects must be at least 18 years old. This study conducted convenience sampling by distributing the questionnaires manually. The questionnaire survey was given to tourists who had visited any of the cultural and creative parks in the 3 regions above. In total, 600 questionnaires were distributed for the following analysis.

\section{Research Results}

\subsection{Reliability and Validity Analysis of Questionnaire}

After the formal questionnaire survey, this study deleted 22 invalid questionnaires and obtained 578 valid ones, for a valid return rate of $96.33 \%$. For the concern of questionnaire reliability, the study conducted reliability and validity analysis on all dimensions. Through Cronbach's $\alpha$, correlation analysis, and factor analysis, it measured reliability and validity of questionnaire. According to the outcome, Cronbach's $\alpha$ of the dimensions is higher than 0.7 (Nunnally, 1978), and the item to total correlation coefficients are above 0.5 (Kerlinger, 1978). This demonstrates that total reliability of the scale is good. This study tested convergent validity of the questionnaire by factor analysis. According to the analysis, the eigenvalues of dimensions are higher than 1 , and the cumulative explained variance is above $50 \%$. Factor loading of the variables in each dimension is higher than 0.5 . Thus, the questionnaire exhibits convergent validity (Kaiser, 1958).

According to analysis of this study, the CR of the latent variables of each dimension is $0.8738 \sim 0.9405$, and they are higher than 0.6. This illustrates good internal consistency of the dimensions. Moreover, the AVE of latent variables is $0.5431 \sim 0.7601$, or higher than 0.5 . It means that items in all dimensions reveal a high degree of consistency (Fornell \& Larcker, 1981) (see Table 1).

Table 1. Reliability and validity analysis of the formal questionnaire

\begin{tabular}{|c|c|c|c|c|c|c|c|c|}
\hline Names of factors & Mean & $\begin{array}{l}\text { Item to total } \\
\text { correlation } \\
\text { coefficient }\end{array}$ & $\begin{array}{l}\text { Factor } \\
\text { loading }\end{array}$ & Eigenvalue & $\begin{array}{l}\text { Cumulative } \\
\text { explained } \\
\text { variance } \%\end{array}$ & $\begin{array}{l}\text { Cronbach } \\
\alpha\end{array}$ & CR & AVE \\
\hline \multicolumn{9}{|l|}{ Surroundings } \\
\hline $\begin{array}{l}\text { There are unique buildings in the } \\
\text { region }\end{array}$ & 5.425 & .704 & .829 & \multirow{6}{*}{3.257} & \multirow{6}{*}{55.238} & \multirow{6}{*}{.8277} & \multirow{6}{*}{0.8738} & \multirow{6}{*}{0.543} \\
\hline $\begin{array}{l}\text { There are local characteristics in } \\
\text { the region }\end{array}$ & 5.701 & .652 & .815 & & & & & \\
\hline $\begin{array}{l}\text { Public construction in the region } \\
\text { is remarkable }\end{array}$ & 5.712 & .610 & .760 & & & & & \\
\hline $\begin{array}{l}\text { There is diversity of landscape in } \\
\text { the region }\end{array}$ & 5.369 & .628 & .759 & & & & & \\
\hline $\begin{array}{l}\text { There are well-known spots in } \\
\text { the region }\end{array}$ & 5.936 & .565 & .678 & & & & & \\
\hline $\begin{array}{l}\text { There are historic relics in the } \\
\text { region }\end{array}$ & 5.425 & .410 & .540 & & & & & \\
\hline \multicolumn{9}{|l|}{ Landmark characteristics } \\
\hline $\begin{array}{l}\text { Content of the cultural and } \\
\text { creative park is rich }\end{array}$ & 5.874 & .829 & .924 & \multirow{4}{*}{3.101} & \multirow{4}{*}{74.893} & \multirow{4}{*}{.8903} & \multirow{4}{*}{0.9372} & \multirow{4}{*}{0.759} \\
\hline $\begin{array}{l}\text { There is unique characteristic in } \\
\text { the cultural and creative park }\end{array}$ & 5.969 & .818 & .911 & & & & & \\
\hline $\begin{array}{l}\text { There is recreational function in } \\
\text { the cultural and creative park }\end{array}$ & 5.985 & .785 & .890 & & & & & \\
\hline $\begin{array}{l}\text { There is social and educational } \\
\text { functions in the cultural and } \\
\text { creative park }\end{array}$ & 6.175 & .640 & .777 & & & & & \\
\hline \multicolumn{9}{|l|}{ Marketing activity } \\
\hline $\begin{array}{l}\text { There are frequent promotion } \\
\text { activities in the cultural and } \\
\text { creative park }\end{array}$ & 5.025 & .885 & .888 & \multirow{4}{*}{3.609} & \multirow{4}{*}{70.698} & \multirow{4}{*}{.9023} & \multirow{4}{*}{0.9288} & \multirow{4}{*}{0.7177} \\
\hline $\begin{array}{l}\text { Advertising information is } \\
\text { common in the cultural and } \\
\text { creative park }\end{array}$ & 4.799 & .796 & .851 & & & & & \\
\hline $\begin{array}{l}\text { Performances are frequently held } \\
\text { in the cultural and creative park }\end{array}$ & 5.092 & .725 & .850 & & & & & \\
\hline Exhibitions are frequently held in & 5.158 & .730 & .838. & & & & & \\
\hline
\end{tabular}




\begin{tabular}{|c|c|c|c|c|c|c|c|c|}
\hline $\begin{array}{l}\text { the cultural and creative park } \\
\text { The cultural and creative park } \\
\text { highlights local cultural } \\
\text { characteristics }\end{array}$ & 4.745 & .711 & .796 & & & & & \\
\hline \multicolumn{9}{|l|}{ Perceived value } \\
\hline $\begin{array}{l}\text { The design of the cultural and } \\
\text { creative park meets the demand }\end{array}$ & 6.100 & .790 & .874 & \multirow{5}{*}{3.398} & \multirow{5}{*}{69.652} & \multirow{5}{*}{.8799} & \multirow{5}{*}{0.9160} & \multirow{5}{*}{0.6852} \\
\hline $\begin{array}{l}\text { The style of the cultural and } \\
\text { creative park is attractive }\end{array}$ & 5.966 & .770 & .859 & & & & & \\
\hline $\begin{array}{l}\text { People have interactions in the } \\
\text { cultural and creative park }\end{array}$ & 5.852 & .750 & .845 & & & & & \\
\hline $\begin{array}{l}\text { The cultural and creative park is } \\
\text { interesting }\end{array}$ & 5.923 & .709 & .819 & & & & & \\
\hline $\begin{array}{l}\text { It is delightful to be in the } \\
\text { cultural and creative park }\end{array}$ & 5.899 & 610 & .740 & & & & & \\
\hline \multicolumn{9}{|l|}{ Regional attraction } \\
\hline $\begin{array}{l}\text { I have the intention to } \\
\text { recommend this cultural and } \\
\text { creative park to others }\end{array}$ & 5.556 & .850 & .911 & \multirow{5}{*}{3.810} & \multirow{5}{*}{75.191} & \multirow{5}{*}{.9132} & \multirow{5}{*}{0.9405} & \multirow{5}{*}{0.7601} \\
\hline $\begin{array}{l}\text { I have high intention to revisit } \\
\text { this cultural and creative park }\end{array}$ & 5.600 & .830 & .890 & & & & & \\
\hline $\begin{array}{l}\text { For travelling, the region is my } \\
\text { priority for destination }\end{array}$ & 5.241 & .811 & .884 & & & & & \\
\hline $\begin{array}{l}\text { I have the intention to participate } \\
\text { in leisure activities introduced in } \\
\text { the region }\end{array}$ & 5.556 & .752 & .839 & & & & & \\
\hline $\begin{array}{l}\text { I have high intention to live in } \\
\text { the region }\end{array}$ & 5.667 & .766 & .837 & & & & & \\
\hline
\end{tabular}

\subsection{Confirmatory Factor Analysis}

In order to validate efficiency of the dimensions, this study adopts AMOS to conduct Confirmatory Factor Analysis (CFA) on the measurement models for the characteristics, surroundings, marketing activities, perceived value, and regional attraction of cultural and creative landmarks. According to Carmines \& MacIver (1981), model fit measures must meet the following standard: ratio of chi-square value and freedom $\leq 3$; RMR (Root mean square residual) and RMSEA (Root mean square error of approximation) are lower than 0.05 ; and GFI (Goodness of fit index), AGFI (Adjusted goodness of fit index), NFI (Normed fit index), and CFI (Comparative fit index) are higher than 0.9 (Bagozzi \& Yi, 1988; Joreskog \& Sorbom, 1989). Thus, this study judges the model fit. According to the analytical results, for the model fit measures, $\chi^{2} / \mathrm{df}$ is 2.985 , GFI is 0.901 , AGFI is 0.897 , NFI is 0.940 , RFI is 0.919 , CFI is 0.957 , RMSEA is 0.045 , and RMR is 0.053 . Hence, model fit is acceptable - that is to say, the indicators reveal construct validity and measurement efficiency.

\subsection{Linear Structural Model Analysis}

This study analyzes the linear structural relationship model through AMOS in order to recognize causal relation and correlation among the variables. According to the previous standard, it validates model fit. The analytical result reveals that GFI, AGFI, NFI, RFI, and CFI are 0.914, 0.895, 0.938, 0.924, and 0.958, respectively; RMSEA and $\chi^{2} / \mathrm{df}$ are 0.046 and 2.388. The outcome meets the standard of good model fit. Thus, the fitness of the structural model is also positive. It shows that the model is acceptable. Based on the analytical result of the correlation among the dimensions, except for the path of the effect of marketing activities on perceived value (H3), which does not support the original hypothesis, the effects of the other paths are significant. Thus, H1, H2, and H4 are supported (see Table 2).

Table 2. Linear structural model analysis

\begin{tabular}{lllll}
\hline Paths & Hypotheses & Results & Estimate parameter & P value \\
\hline Surroundings $\rightarrow$ Perceived value & H1 & support & 0.878 & $* * *$ \\
Landmark characteristics $\rightarrow$ Perceived value & H2 & support & 0.345 & $* * *$ \\
Marketing activity $\rightarrow$ Perceived value & H3 & not support & 0.091 & .179 \\
Perceived value $\rightarrow$ Regional attraction & H4 & support & 0.675 & $* * *$ \\
\hline
\end{tabular}




\section{Conclusion and Suggestions}

\subsection{Research Results and Discussion}

This study respectively selected one cultural and creative landmark that represents Taipei, Taichung, and Kaohsiung of Taiwan (Taipei Songshan Cultural and Creative Park, Kaohsiung Pier-2 Art Center, and Taichung Cultural and Creative Industries Park) as the targets. It explored tourists who had visited any of these landmarks in order to analyze the effects of the characteristics, surroundings, and marketing activities of these cultural and creative landmarks on the public's perceived value and regional attraction, which helped construct the correlation model. By an in-depth study on cultural and creative landmarks, it constructed a new conceptual model and efficient measures and questionnaire scales for academia. They can also serve as important information for a marketing strategy's regional construction and planning.

Research Results:

1) When the surroundings of cultural and creative landmarks are more popular, the public's perceived value is higher; that is to say, natural landscape, public recreational facilities, and historic relics form the overall environmental view for people and influence tourists' emotion and people's value perception (Bitner, Barnes, \& Ward, 1992; Wu \& Zheng, 2014). Therefore, positive surrounding is the key factor for the public's perceived value of cultural and creative landmarks, and it is the most effective one. Thus, the dimension is critical.

2) When characteristics of cultural and creative landmarks are more popular, the public's perceived value is higher; that is to say, when there are recreational functions, entertainment, social education, and regional symbol in cultural and creative landmarks, they meet the functional benefit, symbolic benefit, and experiential benefit proposed by Park, Jaworski, \& MacInnis (1986). Thus, tourists' perceived value can be enhanced.

3) Marketing activities of cultural and creative landmarks do not reinforce tourists' perceived value. The outcome does not support the original hypothesis. The reason could be in that there are not many marketing activities in cultural and creative landmarks of different regions, and they are not regular. They do not impress the tourists. Therefore, the effect is insignificant. This phenomenon can be further explored.

4) When the public's perceived value of cultural and creative landmarks is higher, regional attraction is also higher; it shows that people's perceived value of cultural and creative landmarks is the key moderator to enhance regional attraction. When perceived value is higher, people's future visit intention, revisit intention, residential intention, and recommendation to others are strengthened. This promotes local tourism development. Therefore, it is extremely important to increase the public's perceived value of cultural and creative landmarks.

\subsection{Managerial Implications}

According to research findings, the surrounding factor is the most effective key to enhance the public's perceived value of cultural and creative landmarks. Therefore, in order to increase their perceived value, the government or related authorities should strengthen the planning of the surrounding areas, such as the design of unique buildings and landscape, design excellent public construction and transportation services, and properly utilize original historic relics and stories.

Characteristics of cultural and creative landmarks are also the factors to enhance the public's perceived value. Therefore, how to reinforce the unique features is critical. For instance, the diversity of content of cultural and creative parks should be enhanced. Their unique appearance and memorable image should also be reinforced.

Marketing activities of cultural and creative landmarks in different regions currently do not trigger tourists' value perception. Thus, they should more frequently hold impressive experiential activities that will result in tourists' positive impression and reinforce perceived value. For instance, instruction and the practice of drawing posters in cultural and creative landmarks and landmark model fabrication allow tourists to acquire products by DIY (do-it-yourself), thus enhancing experiential value.

\subsection{Research Limitations and Suggestions}

This study treats tourists who have visited any of the 3 cultural and creative landmarks as subjects in order to probe into the effects of independent variables such as characteristics, surroundings, and marketing activities of cultural and creative landmarks on the public's perceived value and regional attraction. It also constructs the relationship model and obtains the most effective dimension. The subjects filled in questionnaires according to their experience in one of the cultural and creative landmarks. Errors due to different targets are inevitable. Therefore, future research can separately conduct various analyses on the 3 cultural and creative landmarks in order to probe into any differences and any similarity of characteristics as well as the structural relationship models of diverse cultural and creative landmarks. 


\section{Acknowledgement}

This research was made possible through the support of the National Chin-Yi University of Technology, Taiwan, R.O.C. under funding (NCUT 17-R-MB-035).

\section{References}

Agarwal, S., \& Teas, R. K. (2004). Cross-national applicability of a perceived risk-value mode. The Journal of Product and Brand Management, 13(4/5), 242. https://doi.org/10.1108/10610420410546952

Armstrong, G., \& Kotler, P. (2000). Marketing: An Introduction (5th ed.). Prentice Hall: New Jersey.

Babin, B. J., Darden, W. R., \& Griffin, M. (1994). Measuring hedonic and utilitarian shopping value. Journal of Consumer Research, 20, 644-656. https://doi.org/10.1086/209376

Bagozzi, R. P., \& Yi, Y. (1988). On the evaluation of structure equations models. Journal of the Academy of Marketing Science, 16(1), 74-94. https://doi.org/10.1007/BF02723327

Baker, J., Parasuraman, A., Grewal, D., \& Voss, G. B. (2002). The influence of multiple store environment cues on perceived merchandise value and patronage intentions. Journal of Marketing, 66(2), 120-141. https://doi.org/10.1509/jmkg.66.2.120.18470

Baker, S. M. (2006). Consumer normalcy: Understanding the value of shopping through narratives of consumers with visual impairments. Journal of Retailing, 82(1), 37-50. https://doi.org/10.1016/j.jretai.2005.11.003

Beerli, A., \& Martín, J. D. (2004). Factors influencing destination image. Annals of Tourism Research, 31(3), 657-681. https://doi.org/10.1016/j.annals.2004.01.010

Bigne, J. E., Sanchez, M. I., \& Sanchez, J. (2001). Tourism image, evaluation variables and after purchase behaviour: Inter-relationship. Tourism Management, 22(6), 607-616. https://doi.org/10.1016/S0261-5177(01)00035-8

Bitner, M. J. (1992). Servicescapes: Impact of physical surroundings on customers and employees. Journal of Marketing, 56, 57-71. https://doi.org/10.2307/1252042

Bitner, M. J., Barnes, J., \& Ward, J. C. (1992). Measuring the prototypically and meaning of retail environments. Journal of Retailing, 68(3), 192-220.

Blackwell, R. D., Miniard, P. W., \& Engel, J. F. (2001). Consumer Behavior (9th ed.). Mason, OH: South-Western Thomas Learning.

Boulding, W., Kalra, A., Staelin, R., \& Zeithaml, V. A. (1993). A dynamic process model of service quality: From expectation to behavioral intentions. Journal of Marketing Research, 30(1), 7-27. https://doi.org/10.2307/3172510

Carmines, E. G., \& McIver, J. P. (1981). Analyzing models with unobserved variables: analysis of covariance structures. In G. W. Bohrnstedt \& E. F. Borgatta (Ed.), Social measurement: current issues (pp. 65-115). Beverly Hills, Calif: Sage.

Chen, P. J., \& Kerstetter, D. L. (1999). International students' image of Rural Pennsylvania as a travel Destination. Journal of Travel Research, 37(3), 256-266. https://doi.org/10.1177/004728759903700307

Chen, S., \& Quester, P. (2006). Modeling store loyalty: Perceived value in market orientation practice. The Journal of Services Marketing, 20, 188-204. https://doi.org/10.1108/08876040610665643

Crompton, J. L. (1979). An assessment of the image of Mexico as a vacation destination and the influence of geographical location upon the image. Journal of Travel Research, 17(4), 18-24. https://doi.org/10.1177/004728757901700404

Cronin, J. J., \& Taylor, S. A. (1992). Measuring service quality: A reexamination and extension. Journal of Retailing, 56(3), 55-68. https://doi.org/10.2307/1252296

Cronin, J. J., Brady, M. K., \& Hult, G. T M. (2000). Assessing the effects of quality, value, and customer satisfaction on consumer behavioral intentions in service environments. Journal of Retailing, 76(2), 193-218. https://doi.org/10.1016/S0022-4359(00)00028-2

Dodds, W. B., Monroe, K., \& Grewal, D. (1991). The effects of price, brand and store information on buyers' product evaluations. Journal of Marketing Research, 28, 307-319. https://doi.org/10.2307/3172866

Fakeye, P. C., \& Crompton, J. L. (1991). Image differences between prospective, first-time, and repeat visitors to the lower Rio Grande Valley. Journal of Travel Research, 30(2), 10-16. 
https://doi.org/10.1177/004728759103000202

Fornell, C. R., \& Larcker, F. F. (1981). Structural equation models with unobservable variables and measurement error. Journal of Marketing Research, 18, 39-51. https://doi.org/10.2307/3151312

Gronholdt, L., Martensen, A., \& Kristensen, K. (2000). The relationship between customer satisfaction and loyalty: Cross-industry differences. Total Quality Management, 11(4-6), 509-514. https://doi.org/10.1080/09544120050007823

Harrell, G. D., Hutt, M. D., \& Anderson, J. C. (1980). Path analysis of buyer behavior under conditions of crowding. Journal of Marketing Research, 17, 45-51. https://doi.org/10.2307/3151115

Hu, Y., \& Ritchie, J. R. (1993). Measuring destination attractiveness: A contextual approach. Journal of Travel Research, 4, 2-34.

Jochen, W., \& John, E. G. B. (1999). Consumer satisfaction with service: Integrating the environment perspective in service marketing into the traditional disconfirmation paradigm. Journal of Business Research, 44(1), 55-66.

Joreskog, K. G., \& Sorbom, D. (1989). LISREL 7 user's reference guide. Chicago: Scientific Software Inc.

Kaiser, H. F. (1958). The varimax criterion for analysis rotation in factor analysis, Psychometrika, 23(3), 187-200. https://doi.org/10.1007/BF02289233

Keller, K. L. (1993). Conceptualizing, measuring, and managing consumer-based brand equity. Journal of Marketing, 57(1), 1-22. https://doi.org/10.2307/1252054

Kerlinger, F. N. (1978). Foundation of behavioral research. New York: McGraw-Hill.

Kotler, P., Haider, D. H., \& Rein, I. (1993). Marketing Places: Attracting Investment, Industry and Tourism to Cities, States, and Nations. NY: Maxwell Macmillan Inc.

Lee, E. J., Uniremidy, C. A., \& Overby, J. W. (2004). Creating value for online, shoppers: Implications for satisfaction and loyalty. Journal of Consumer Satisfaction, Dissatisfaction \& Complaining Behavior's Primary Objective, 17, 54-67.

Leisen, B. (2001). Image segmentation: The case of a tourism destination. Journal of Services Marketing, 15(1), 49-66. https://doi.org/10.1108/08876040110381517

MacKay, K. J., \& Fesenmaier, D. R. (1997). Pictorial element of destination in image formation. Annals of Tourism Research, 24(3), 537-565. https://doi.org/10.1016/S0160-7383(97)00011-X

Martin, H. S., \& Del Bosque, I. A. R. (2008). Exploring the cognitive-affective nature of destination image and the role of psychological factors in its formation. Tourism Management, 29(2), 263-277. https://doi.org/10.1016/j.tourman.2007.03.012

Ministry of Culture. (2013). 2013 Cultural news, Taiwan.

Montgomery, J. (2003). Cultural quarters as mechanisms for urban regeneration. Part 1: Conceptualizing cultural quarters. Planning, Practice and Research, 18(4), 293-306. https://doi.org/10.1080/1561426042000215614

Montgomery, J. (2004). Cultural quarters as mechanisms for urban regeneration. Part 2: A review of four cultural quarters in the UK, Ireland and Australia. Planning Practiced Research, 19(1), 3-31. https://doi.org/10.1080/0269745042000246559

Nunnally, J. C. (1978). Psychometric theory. New York: McGraw-Hill.

Park, C. W., Jaworski, B. J., \& MacInnis, D. J. (1986). Strategic brand concept image management. Journal of Marketing, 50(1), 62-78. https://doi.org/10.2307/1251291

Pine, B. J., \& Gilmore, J. H. (2003). The Experience Economy. Taipei: Cite Publishing Ltd.

Richardson, P. S., Dick, A. S., \& Jain, A. K. (1994). Extrinsic and extrinsic cue effect on perceptions of Store Brand quality. Journal of Marketing Research, 58(4), 28-36. https://doi.org/10.2307/1251914

Romaniuk, J., \& Sharp, B. (2003). Measuring brand perceptions: Testing quantity and quality. Journal of Targeting, Measurement and Analysis for Marketing, 11(3), 218-229. https://doi.org/10.1057/palgrave.jt.5740079

Schmitt, B. (1999). Experiential marketing. Journal of Marketing Management, 15(1-3), 53-67. https://doi.org/10.1362/026725799784870496

Sweeney, J. C., \& Soutar, G. N. (2001). Consumer perceived value: The development of a multiple item scale. 
Journal of Retailing, 77(2), 203-220. https://doi.org/10.1016/S0022-4359(01)00041-0

Turner, A. (2001). Brand=experience. Marketing Magazine, 6(27), 16.

Wu, S. I., \& Huang, L. C. (2015). The impact of physical environment and regional image on tourist's experiential values and feelings-An example of Nanzhuang area in Taiwan. International Journal of Business and Management, 10(11), 94-106. https://doi.org/10.5539/ijbm.v10n11p94

Wu, S. I., \& Liou, N. W. (2015). Impact of city social responsibility and marketing strategy on city image and people's perception. Journal of Management and Sustainability, 5(4), 30-43. https://doi.org/10.5539/jms.v5n4p30

Wu, S. I., \& Zheng, Y. H. (2014). The Influence of tourism image and activities appeal on tourist loyalty-A study of Tainan city in Taiwan. Journal of Management and Strategy, 5(4), 121-135. https://doi.org/10.5430/jms.v5n4p121

Zeithaml, V. A. (1988). Consumer perceptions of price, quality, and value: A means-end model and synthesis of evidence. Journal of Marketing, 52(3), 2-22. https://doi.org/10.2307/1251446

\section{Copyrights}

Copyright for this article is retained by the author(s), with first publication rights granted to the journal.

This is an open-access article distributed under the terms and conditions of the Creative Commons Attribution license (http://creativecommons.org/licenses/by/4.0/). 